\title{
The Conservation Reserve Program in the Presence of a Working Land Alternative: Implications for Environmental Quality, Program Participation, and Income Transfer
}

\author{
Hongli Feng, Catherine L. Kling, Lyubov A. Kurkalova, \\ Silvia Secchi, and Philip W. Gassman
}

Working Paper 05-WP 402

August 2005

\author{
Center for Agricultural and Rural Development \\ lowa State University \\ Ames, lowa 50011-1070 \\ www.card.iastate.edu
}

\begin{abstract}
Hongli Feng is associate scientist at the Center for Agricultural and Rural Development (CARD), Catherine Kling is professor of economics and head of the Resource and Environmental Policy Division at CARD, Silvia Secchi is associate scientist at CARD, and Philip Gassman is assistant scientist at CARD, all at lowa State University. Lyubov Kurkalova is assistant professor at the Department of Agribusiness Economics at Southern Illinois University. The authors thank Todd Campbell for excellent computational assistance.
\end{abstract}

Financial support from the Consortium for Agricultural Soil Mitigation of Greenhouse Gases and the U.S. Environmental Protection Agency is appreciated.

This paper is available online on the CARD Web site: www.card.iastate.edu. Permission is granted to reproduce this information with appropriate attribution to the authors. This paper will appear in the December 2005 issue of the American Journal of Agricultural Economics. It was presented as a principal paper, "Cost-Effectiveness of the Conservation Reserve Program: Current Challenges," at the 2005 American Agricultural Economics Association annual meeting in Providence, Rhode Island.

For questions or comments about the contents of this paper, please contact Hongli Feng, 560D Heady Hall, lowa State University, Ames, IA 50011-1070; Ph: (515) 294-6307; Fax: (515) 2946336; E-mail: hfeng@iastate.edu. 


\begin{abstract}
The United States has invested large sums of resources in multiple conservation programs for agriculture over the past century. In this paper we focus on the impacts of program interactions. Specifically, using an integrated economic and bio-physical modeling framework, we consider the impacts of the presence of working land programs on a land retirement for an important agricultural region-the Upper Mississippi River Basin (UMRB). Compared to a land retirement only program, we find that the presence of a working land program for conservation tillage results in significantly lower predicted signups for land retirement at a given rental rate. We also find that the presence of both a large working land and land retirement program can result in more environmental benefits and income transfers than a land retirement only program can achieve.
\end{abstract}

Keywords: Conservation Reserve Program, conservation tillage, environmental quality, income transfer, working land programs. 


\section{THE CONSERVATION RESERVE PROGRAM IN THE PRESENCE OF A WORKING LAND ALTERNATIVE: IMPLICATIONS FOR ENVIRONMENTAL QUALITY, PROGRAM PARTICIPATION, AND INCOME TRANSFER}

The United States has invested a large amount of resources in conservation programs for agriculture over the past century. Beginning in 1985, the largest and most ambitious conservation program, the Conservation Reserve Program (CRP), was introduced with dual goals of controlling supply and reducing soil erosion. As reported in Claassen et al. 2001 , over $\$ 15$ billion dollars was spent in the first 15 years, which resulted in the retirement of about 10 percent of total cropland across the country from active production.

The CRP provides payments to farmers to retire environmentally sensitive land from active crop production and establish environmentally beneficial cover for the length of a contract, typically 10 to 15 years. Although the CRP has evolved to target a broad array of environmental benefits, it operates strictly through land retirement. For land remaining in production, so-called working land, other programs have been instituted, such as the Environmental Quality Incentive Program (EQIP) and the newly initiated Conservation Security Program (CSP), both of which encourage the adoption/maintenance of conservation practices on working land.

A number of important investigations of the CRP have been undertaken and much insight concerning the efficiency and shortcomings of the program has been gained. ${ }^{1}$ However, one issue that has not received much attention is the consequences of working land programs that compete for the same parcels of land. This question is particularly relevant in light of the CSP, which, for the first time, makes direct payments for the adoption of conservation practices on working land that explicitly cover their full opportunity cost. Previous programs, notably EQIP, pay only a share of the total cost of a practice and thus less directly compete with the CRP for participants. The design and magnitude of both the CRP and the CSP appear to be central topics on the agenda of environmental discussions related to the 2007 farm bill. Thus, it will be increasingly important to under- 
stand the potential complementarities and conflicts between these two programs. In this paper, we consider the consequences of a working land program for the performance of a land retirement program measured in terms of cost, program enrollment, environmental effectiveness, and income transfer.

Faced simultaneously with programs for land retirement and conservation practices on working land, farmers must decide whether to retire a piece of land and enroll it in CRP, to cultivate the land with conservation practices and receive a payment, or not to participate in either program. Their decision will affect the efficacy of each individual program. While the literature indicates that targeting conservation payments can result in more effective use of conservation budgets, targeting in the presence of multiple conservation programs has not been given adequate attention. Yet it is important to understand the interaction of programs in order to assess properly the effectiveness of the existing portfolio of programs.

In this paper, we estimate how the existence of conservation programs similar to EQIP and CSP might affect the CRP in terms of land enrolled, income transfers to farmers, and the extent of environmental improvement, as measured by agricultural soil carbon sequestration, reduction in soil erosion, and reduction in nitrogen runoff. We show that, compared to the case where land retirement is the only option, the economic and environmental results of a land retirement program are very different when working land programs are also available. For example, we show that the same unit payments for land retirement in the presence of subsidies for conservation tillage can enroll only about half of the acreage that can be enrolled in the absence of such subsidies.

We consider these program interactions for a critically important agricultural region of the country - the Upper Mississippi River Basin (UMRB), with an area of 189,000 square miles. The map on the left in Figure 1 shows the location of the UMRB in the United States and the Mississippi River Basin (the dark shaded area). The map on the right in Figure 1 displays the boundaries of the 14 U.S. Geological Service four-digit subwatersheds and the percentage of crop and pasture land in each watershed (the numbers in parentheses). The UMRB is dominated by agriculture (NAS 2000): cropland and pasture together account for nearly 67 percent of the total area, with the percentage varying significantly by sub-watershed, as shown in Figure 1 . The area is estimated to be the 

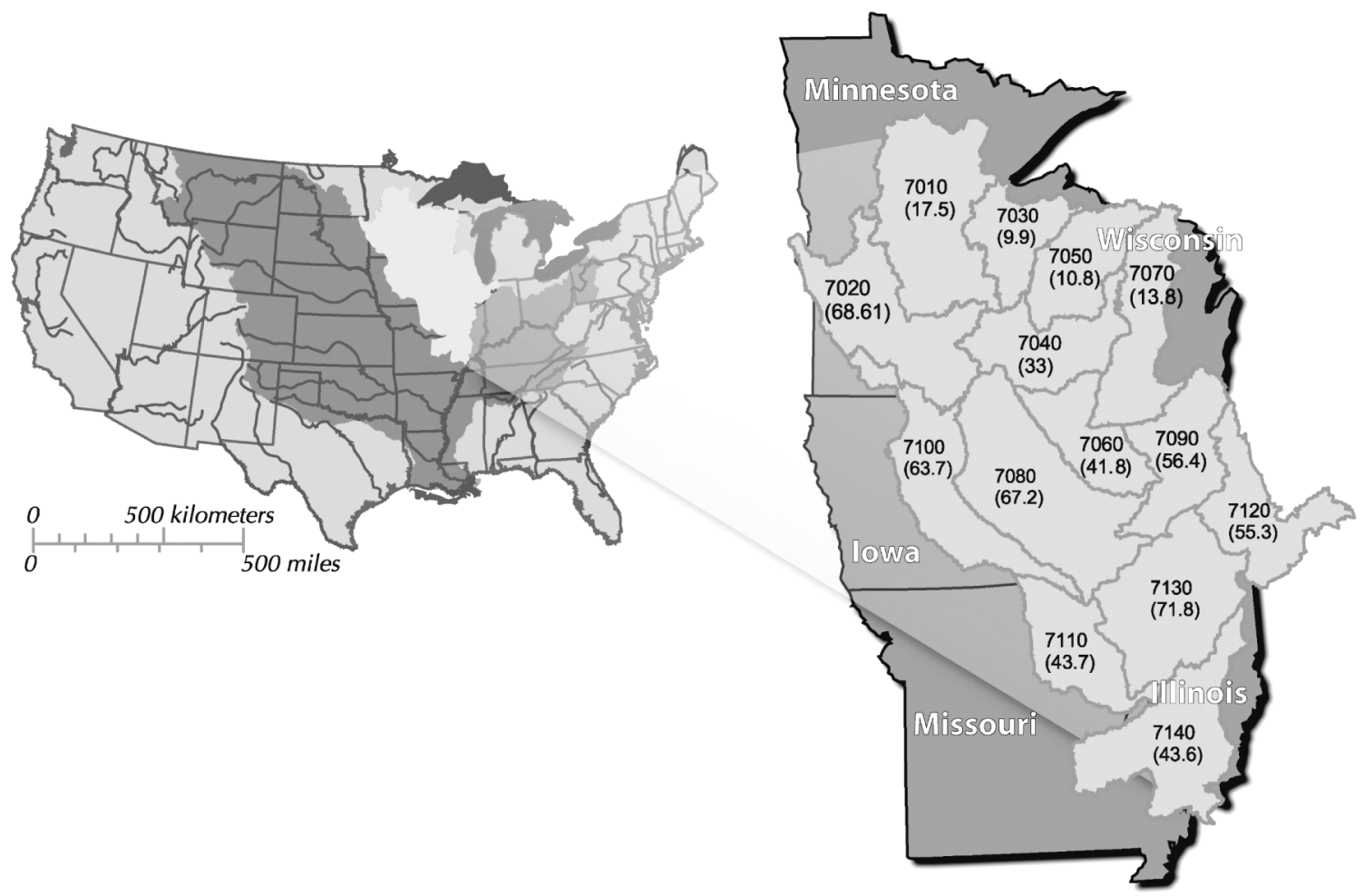

FIGURE 1. The Upper Mississippi River Basin: percentage of area under cropland by sub-watersheds

source of nearly 40 percent of the Mississippi nitrate load discharged during 1980-1986 (Goolsby et al. 1999), a prime suspect in the cause of the oxygen-depleted hypoxic zone in the Gulf of Mexico, which covered nearly 20,000 square kilometers in 1999 (Rabalais, Turner, and Scavia 2002). The UMRB also has lakes with the highest concentrations of phosphorous found in the world.

We turn now to the policies analyzed, followed by a description of the integrated economic and biophysical model simulation framework used in the analysis. Then we present results and policy implications of the analysis.

\section{Policy Scenarios}

We assess conservation policies that would provide green payments (subsidies) for the retirement of land from active production or for the adoption of a major on-farm conservation practice, conservation tillage. ${ }^{2}$ We compare and contrast a policy that simultaneously offers payments for conservation tillage — a working land practice—with land retirement 
policies that offer payments solely for land retirement. The purpose of this comparison is to determine the effect that a second program that competes for the usage of agricultural land for environmental benefits has on the efficacy and cost of the CRP.

Specifically, we analyze three scenarios. In the first, which we term "CRP with CT," producers are offered a per-acre subsidy to retire land from active production or they can choose a subsidy (of different value) to adopt conservation tillage and keep their land in active production. ${ }^{3}$ Given the policy, farmers have three alternatives: produce with conventional tillage, produce with conservation tillage and receive the tillage subsidy, or retire land from production in exchange for the retirement subsidy. We assume that farmers will choose between the two subsidies by maximizing the difference between the subsidy offered and the producer's opportunity cost. If neither subsidy exceeds the corresponding opportunity cost, the farmer produces with conventional tillage.

In the remaining two scenarios, the subsidies are only offered for retiring land from production. These two scenarios provide a meaningful comparison with the first scenario by holding constant either the per-acre payments for land retirement or the total program costs. In the scenario "CRP equal payment," the per-acre payment schedule for land retirement is the same as "CRP with CT," although no payments are offered for conservation tillage. However, in the third scenario "CRP equal budget," the total payments are set equal to those in "CRP with CT" in each sub-watershed. The per-acre payments are thus determined endogenously so that, for any given sub-watershed, land is retired until the same total expenditure is met as under "CRP with CT." Thus, by construction, the first two scenarios have different total program costs but the same per-acre land retirement payments and the first and third have different per-acre payments but the same total expenditure. The purpose of the second two scenarios is to compare the efficiency and distributional consequences of a single land retirement program with a program that includes both working land and land retirement opportunities.

In devising the subsidy levels in these three scenarios, it is most relevant to account explicitly for geographic cost variability so we let the per-acre subsidies differ by the subwatersheds. This watershed-based geographical approach is consistent with the present administration of the CSP. In the first two scenarios, the conservation tillage subsidy is set at each sub-watershed's median of conservation tillage adoption costs (as predicted by 
The Conservation Reserve Program in the Presence of a Working Land Alternative / 5

our empirical model), and the land retirement subsidy is set at the 10th percentile of land retirement costs in the sub-watershed.

\section{Data and Integrated Modeling Framework}

The analysis of the conservation policies is undertaken using an integrated modeling framework that combines economic and biophysical models. Our analysis preserves the micro-level heterogeneity of individual farmers' behavior while at the same time allowing consideration of multiple environmental indicators at the sub-watershed and large landscape levels.

\section{Data}

The data come primarily from the 1997 National Resources Inventory (NRI) (USDA-NRCS 1997), which provides information on the natural resource characteristics of the land, cropping history, conservation practices used by producers, and other data for some 37,500 cropland physical points. In the analysis, each NRI point is treated as a producer with land homogenous in land use, soil, and other characteristics. The farm size is assumed to equal the number of acres represented by the point, which generally ranges from a few hundred to several thousand acres in size. Because the data are statistically reliable for state and multi-county analysis of non-federal land, they are representative of the agricultural land in the UMRB. ${ }^{4}$

\section{Costs of Conservation Practices}

To estimate the opportunity cost of conservation tillage adoption, we employ a discrete choice model that assumes a producer will adopt conservation tillage when the net returns from this farming practice exceed those from conventional tillage plus a risk premium. Separate models are fit for each of the sub-watersheds; details on data, model selection, and estimation, as well as parameter estimates, are provided in Sengupta, Kurkalova, and Kling 2005. Since the 1997 NRI does not have information on the use of conservation tillage, the econometric models are first estimated using the 1992 NRI and then calibrated to the 1997 sub-watershed-average conservation tillage adoption rates provided by the Conservation Technology Information Center (CTIC 2000), using the procedure described in Feng et al. 2004. We use the calibrated models to predict 1997 NRI tillage baseline, that is, which 
points use conservation as opposed to conventional tillage, as well as to estimate pointspecific subsidies needed for the adoption of conservation tillage for the data points that are predicted to currently employ conventional tillage.

Following Smith (1995), we model the opportunity cost of enrollment in CRP via cropland cash rental rates. The point-specific cropland cash rental rates for all the NRI points in the region are calculated using a set of piece-wise linear functions that relate the yield potential to the cash rental rate. Kurkalova, Burkart, and Secchi (2004) describe the separate functions estimated for each state and, where possible, for each sub-region.

\section{Environmental Benefits of Conservation Practices}

Three environmental benefits of conservation tillage adoption and enrollment in CRP — soil carbon sequestration, erosion reduction, and nitrogen runoff reduction—are estimated at each of the data points using the Environmental Policy Integrated Climate (EPIC) model, version 3060 (Izaurralde et al. 2005 and Williams 1990). ${ }^{5}$ The EPIC model simulates crop growth processes and nutrient cycles at a field-scale level for areas homogeneous in weather, soil, landscape, crop rotation, and management system parameters.

To derive the environmental results under conventional tillage for an NRI point, we ran EPIC simulations at the point for a 30-year period and then obtained annual averages of changes in environmental indicators (e.g., erosion reduction) during the simulation period. Similarly, we derived the annual averages of changes in the same environmental indicators when the point is under conservation tillage or land retirement with grass cover. Then, environmental benefits for conservation tillage were derived as the difference between the annual averages for conservation and conventional tillage. Likewise, environmental benefits for land retirement were derived as the difference between the annual averages for land retirement and whichever tillage method is currently used.

Policy outcomes under the three scenarios were simulated by first utilizing the economic models to predict (1) which of the NRI points in the region will enroll in CRP and conservation tillage in response to the green payments offered and (2) to estimate the costs of the policies together with the income transfer captured by farmers. The predicted enrollment in conservation programs was then combined with the EPIC-based estimates of carbon sequestration, erosion reduction, and nitrogen runoff reduction to predict the environmental improvement attributable to each policy. 
The Conservation Reserve Program in the Presence of a Working Land Alternative / 7

\section{Results}

\section{Program Participation and Economic Welfare}

Economic outcomes of the scenarios by sub-watersheds and the full study region are reported in Tables 1 and 2. In Table 1, the effects of alternative scenarios are compared. First, by construction, "CRP equal payment" retires 10 percent of land. However, when the land retirement program co-exists with the conservation tillage program ("CRP with CT"), the CRP participation drops sharply: only 5 percent of land is now retired. This occurs because half of those fields, where payments for both land retirement and conservation tillage exceed their respective costs, enroll in conservation tillage because of its higher transfer. Interestingly, the effect of the higher transfer is more pronounced in the southern sub-watersheds of the UMRB (sub-watersheds 7110 through 7140), where in some cases only 2 percent would enroll in CRP if payments for conservation tillage are also offered. These findings imply that analyses of CRP that ignore other programs may be misleading.

Second by comparing the "CRP with CT" and "CRP equal budget" scenarios, we see that, with the same expenditures, a land-retirement-only program could enroll about 25 percent of total cropland. While the total acreage of retired land increases from 5 percent to 25 percent, the average price for land retirement only increases from $\$ 85$ to $\$ 97$ per acre. Since the payment is uniform within a watershed (again by construction), it is not surprising that the average transfer payment is higher in the "CRP equal budget" scenario than in the "CRP with CT" scenario. This is because, as more land is enrolled, the unit payment increases and the farmers with lower opportunity cost receive larger transfers.

In addition, the effects are quite heterogeneous across the watersheds. Because the costs of adopting conservation practices vary significantly both across and within the subwatersheds, the income transfer on CRP land varies significantly by sub-watershed and by scenario. For example, sub-watershed 7030 receives very low transfer per acre, which varies from $\$ 1.4$ per acre under “CRP equal payment" to $\$ 2.6$ per acre under "CRP equal budget." In contrast, sub-watersheds 7020, 7060, 7080, 7090, and 7100 all get a transfer of consistently more than $\$ 10$ per acre in all three scenarios. The ranking of subwatersheds on this measure, however, is not independent of the scenario: the highest transfer under "CRP with CT," almost \$17 per acre, is achieved in sub-watershed 7080. 


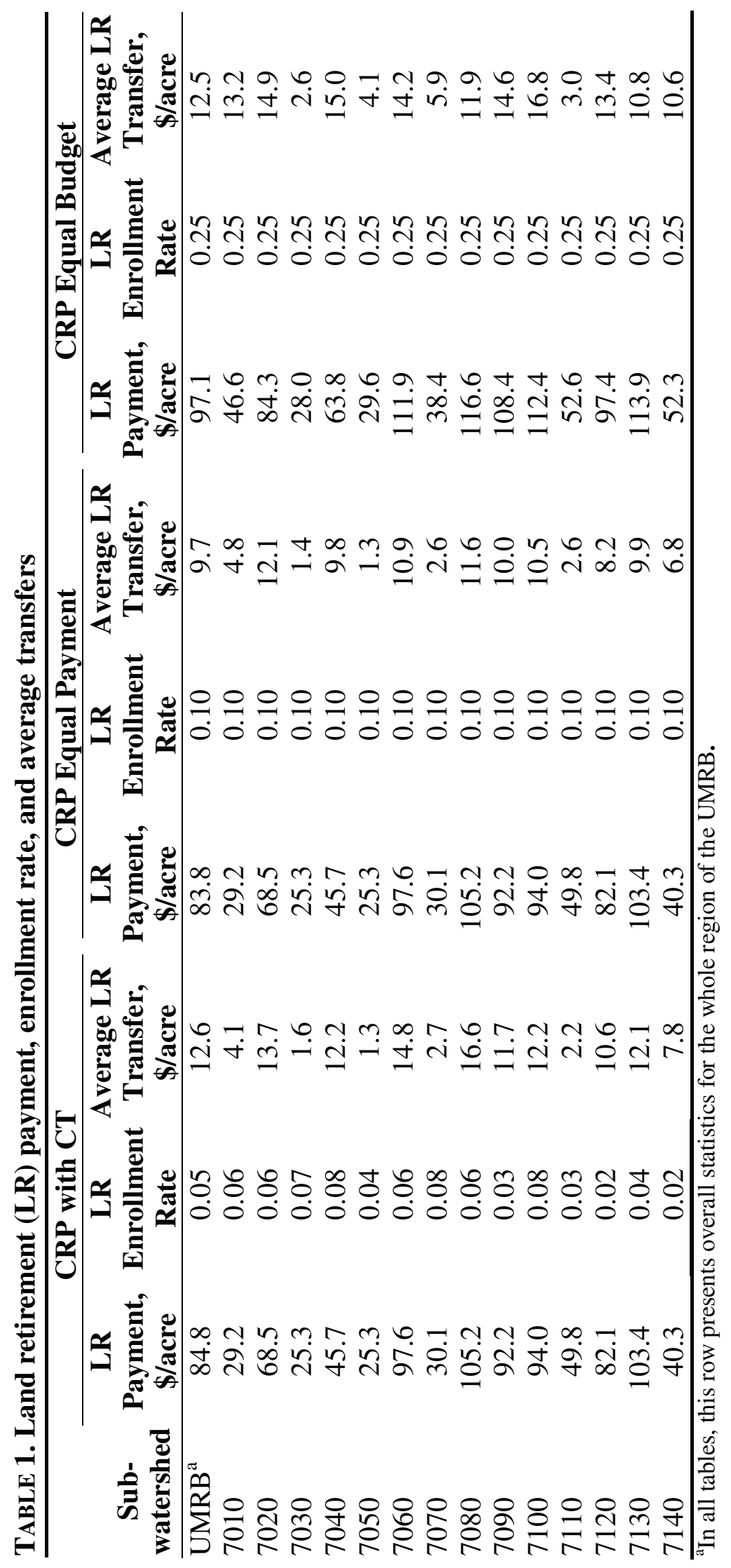




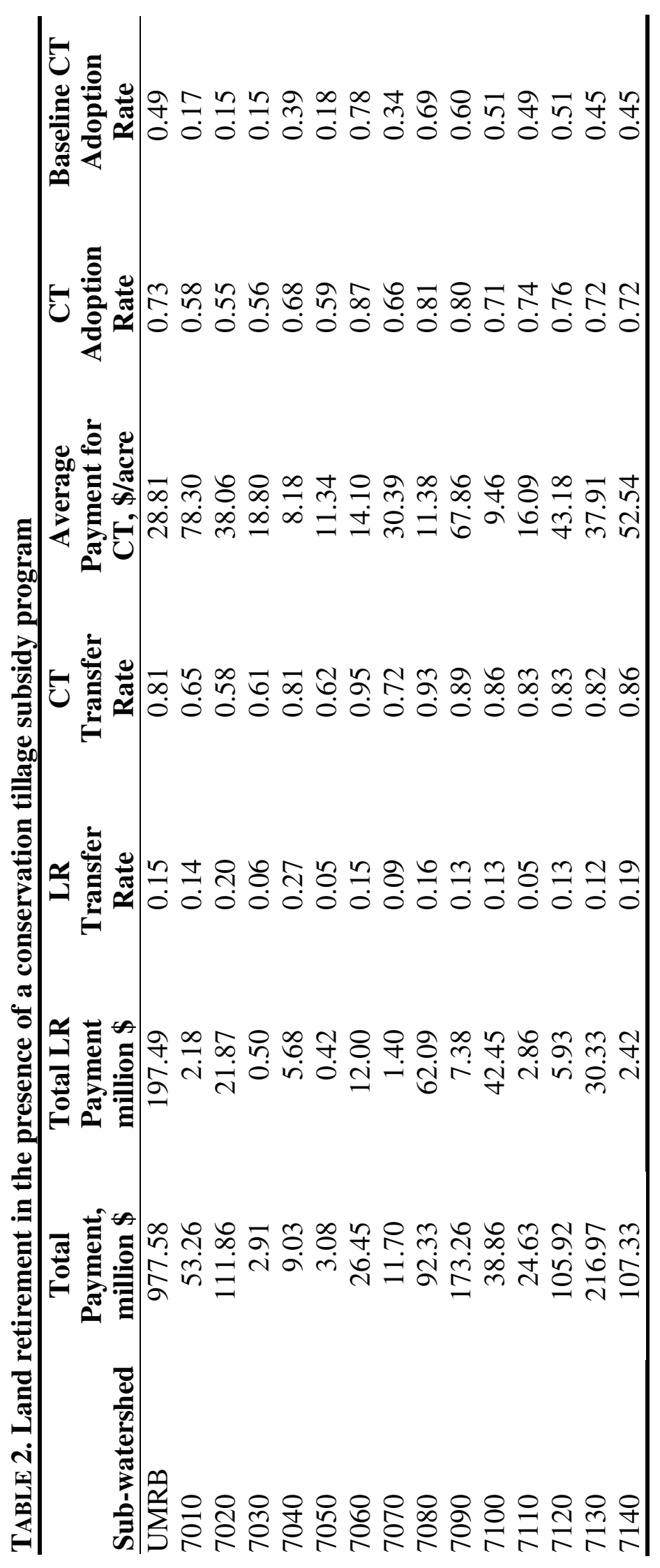


However, for the other two scenarios, sub-watersheds 7020 and 7100 are ranked the highest, with transfers of $\$ 12.1$ and $\$ 16.8$ per acre, respectively.

Table 2 provides more insight by comparing the results on land retirement and conservation tillage when payments are offered for both of them. Not unexpectedly, the policy is expensive, with the overall cost exceeding $\$ 1.1$ billion. However, the largest share of the program cost, over 70 percent of the total expenditure, is an income transfer, given by the sum of producer surpluses retained by the farmers whose opportunity costs fall below the subsidies. The average per-acre payment is $\$ 29$ for adoption of conservation tillage and $\$ 85$ for land retirement. In addition, the average transfer payment from land retirement is over $\$ 10$ per acre less than the transfer payment through conservation tillage. ${ }^{6}$ The difference is even more pronounced in terms of the percentage transfer: the overall average transfer rates are 15 and 81 percent for land retirement and conservation tillage, respectively.

As shown in the last column of Table 2, there is already a significant proportion of current adopters of conservation tillage (i.e., farmers who have already adopted conservation tillage before the introduction of payments), and thus significantly more acres are being paid for the practice. This results from our assumption that current adopters are eligible for payment; relaxing this assumption would reverse the result. Because of this higher rate of participation, the total payment of conservation tillage is considerably higher than that for land retirement even though the per-acre payment for land retirement is almost three times higher.

\section{Environmental Indicators}

In Table 3, we present the results of the environmental quality changes, including carbon sequestration, ${ }^{7}$ soil erosion reduction, and nutrient runoff for the "CRP with CT" and "CRP equal budget" scenarios since these two represent the same total expenditures. Two pairs of columns with results are presented for each variable: first the level of the variable is reported for the "CRP with CT" scenario, and next to it the percentage of the first column's scenario for the "CRP equal budget" is presented. Thus, the total land area affected in "CRP with CT" is about 35 million acres; only about a third of that size is 
The Conservation Preserve Program in the Presence of a Working Land Alternative / 11

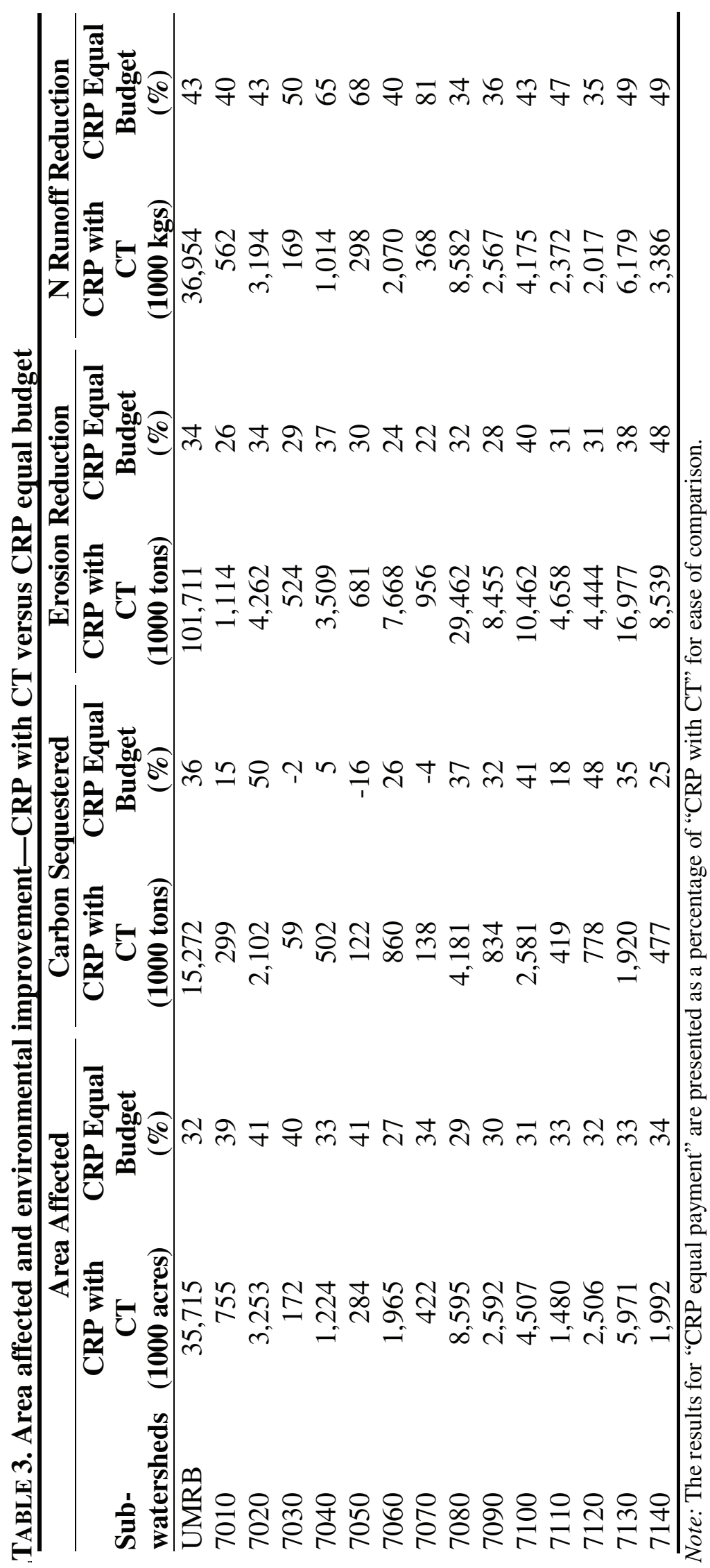


affected in the "CRP equal budget" scenario (11 million acres). The difference in size is also reflected in the total amount of carbon sequestered and erosion and nitrogen runoff reduced. This is consistent with the findings of Feng et al. (2004) who found that for carbon sequestration, conservation tillage is significantly more cost-effective than is land retirement in Iowa. Note that "CRP with CT" is something of a win-win situation in the sense that both the transfer rate and the environmental benefits are higher than in the other two scenarios. As with the program participation and economic outcomes, as shown in Table 3, the sub-watersheds contribute very differing amounts of environmental benefits to the total and they further differ by scenario among the sub-watersheds. Under "CRP equal budget," sub-watershed 7010 enrolls more than the UMRB-average percentage of "CRP with CT" but provides less than the UMRB-average percentages of its environmental benefits. The opposite is true for sub-watershed 7100, for which the environmental outcomes are still worse than in the "CRP with CT" outcomes but are somewhat better than the UMRB-averages.

\section{Concluding Remarks}

Working land and land retirement programs are mutually exclusive in the sense that a single plot of land can be enrolled in one or the other of these programs but not in both simultaneously. This fact means that the programs compete with one another for land, and the program choices that landowners make may have significant consequences for the performance of each program. The point is not whether it is superior to have a single or multiple programs, as both programs appear here to stay and both programs provide important benefits. Rather, the point of this research is to underscore the fact that the impact of one program on another is critical at all stages of conservation policy, from their design to their implementation to final assessment of their efficacy.

Indeed, the Conservation Effects Assessment Program of the U.S. Department of Agriculture is currently assessing the effectiveness of conservation programs such as the CRP; without clearly accounting for the interaction with other programs, such assessments could produce inaccurate results or an incomplete picture. Rather than assess each program individually, it may be more fruitful to consider whether the bundle of conservation practices induced by the various portfolios of programs is efficient. 
Our results suggest that these program interactions may be significant. Specifically, the presence of a working land program for conservation tillage that directly competes with a land retirement program for enrollment was found in our simulation analysis to result in significantly lower predicted sign-ups for land retirement at a given rental rate. We also find that the presence of both a large working land program and a land retirement program can result in more environmental benefits and income transfers than land retirement can achieve alone. 


\section{Endnotes}

1. For a sample of important works in this area, see Osborne 1993; Reichelderfer and Boggess 1988; Babcock et al. 1996, 1997; Goodwin and Smith 2003; Feather, Hellerstein, and Hansen 1999; and Wu 2000.

2. While there are many conservation practices that can be implemented on working land, conservation tillage is generally viewed as one of the most cost-effective. It is therefore a good choice for comparison with land retirement programs that can be quite costly.

3. We assume that farmers receive the tillage subsidy even if they have already implemented conservation tillage practices as a reward for good stewardship. This assumption could easily be relaxed.

4. Other data used in cost estimation and environmental modeling are further described in what follows.

5. Earlier versions of EPIC were called Erosion Productivity Impact Calculator (Williams 1990).

6. The CT transfer rate can be computed by multiplying the average CT payment by the average transfer rate in Table 2.

7. Total carbon sequestration is negative for some watersheds under the landretirement-only scenarios (HUCs 7030, 7040, 7070). This is because carbon sequestration is measured as the difference between land retirement and conventional tillage. For some rotations (e.g., rotations with alfalfa), the carbon sequestration potential for retired land with grass cover is not as high as when the land remains as working land. 


\section{References}

Babcock, B.A., P.G. Lakshminarayan, J. Wu, and D. Zilberman. 1996. "The Economics of a Public Fund for Environmental Amenities: A Study of CRP Contracts." American Journal of Agricultural Economics 78: 961-71.

Babcock, B.A., P.G. Lakshminarayan, J. Wu, and D. Zilberman. 1997. "Targeting Tools for the Purchase of Environmental Amenities." Land Economics 73: 325-39.

Claassen, R., L. Hansen, M. Peters, V. Breneman, M. Weinberg, A. Cattaneo, P. Feather, D. Gadsby, D. Hellerstein, J. Hopkins, P. Johnston, M. Morehart, and M. Smith. 2001. "Agri-Environmental Policy at the Crossroads: Guideposts on a Changing Landscape." Agricultural Economics Report No. 794. Economic Research Service, U.S. Department of Agriculture.

Conservation Tillage Information Center (CTIC). 2000. "2000 Crop Residue Management Survey, National Association of Conservation Districts." West Layfayette, IN. Available at http://www.ctic.purdue.edu/ CTIC/CTIC.html (accessed August 2005).

Feather, P., D. Hellerstein, and L. Hansen. 1999. "Economic Valuation of Environmental Benefits and the Targeting of Conservation Programs: The Case of the CRP." Agricultural Economics Report No. 778. Economics Research Service, U.S. Department of Agriculture. April.

Feng, H., L.A. Kurkalova, C.L. Kling, and P.W. Gassman. 2004. "Environmental Conservation in Agriculture: Land Retirement versus Changing Practices on Working Land." CARD Working Paper 04WP 365. Center for Agricultural and Rural Development, Iowa State University.

Goodwin, B.K., and V.H. Smith. 2003. "An Ex Post Evaluation of the Conservation Reserve, Federal Crop Insurance, and Other Government Programs: Program Participation and Soil Erosion." Journal of Agricultural and Resource Economics 28: 201-16.

Goolsby, D.A., W.A. Battaglin, G.B. Lawrence, R.S. Artz, B.T. Aulenbach, R.P. Hooper, D.R. Keeney, and G.J. Stensland. 1999. "Flux and Sources of Nutrients in the Mississippi-Atchafalaya River Basin: Topic 3 Report for the Integrated Assessment on Hypoxia in the Gulf of Mexico.” NOAA Coastal Ocean Program Decision Analysis Series No. 17. U.S. Department of Commerce. Available at http://www.nos.noaa.gov/products/hypox_t3final.pdf (accessed August 2005).

Izaurralde, R.C., J.R. Williams, W.B. McGill, and N.J. Rosenberg. 2005. "Modeling Soil Organic Carbon Changes in CRP and a Long-Term Crop Rotation Trial with EPIC." Working Paper. Pacific Northwest National Laboratory, Richland, WA.

Kurkalova, L.A., C. Burkart, and S. Secchi. 2004. "Cropland Cash Rental Rates in the Upper Mississippi River Basin." CARD Technical Report 04-TR 47. Center for Agricultural and Rural Development, Iowa State University.

National Audubon Society (NAS). 2000. "The Changing Face of the UMR Basin Agriculture: Selected Profiles of Farming and Farm Practices.” NAS, Upper Mississippi River Campaign, St. Paul, MN. Available at: http://www.umbsn.org/news/documents/chg_face.pdf (accessed August 2005). 
Osborne, T. 1993. "The Conservation Reserve Program: Status, Future, and Policy Options." Journal of Soil and Water Conservation 48(July-August): 271-78.

Rabalais, N.N., R.E. Turner, and D. Scavia. "Beyond Science into Policy: Gulf of Mexico Hypoxia and the Mississippi River.” BioScience 52(2002):129-42.

Reichelderfer, K., and W. Boggess. 1988. "Government Decision Making and Program Performance: The Case of the Conservation Reserve Program." American Journal of Agricultural Economics 70: 1-11.

Sengupta, S., L.A. Kurkalova, and C.L. Kling. 2005. "Overcoming Model Selection Bias in Estimating Discrete Choice Models: An Application to Conservation Tillage Adoption." Unpublished manuscript. Center for Agricultural and Rural Development, Iowa State University.

Smith, R.B.W. 1995. "The Conservation Reserve Program as a Least-Cost Land Retirement Mechanism." American Journal of Agricultural Economics 77(February): 93-105.

U.S. Department of Agriculture, National Resource Conservation Service (USDA-NRCS). 1997. National Resource Inventory. Data File. Available at: http://www.nrcs.usda.gov/technical/nri/1997 (accessed August 2005).

Williams, J.R. 1990. "The Erosion Productivity Impact Calculator (EPIC) Model: A Case History." Philosophical Transactions of the Royal Society, London 329: 421-28.

Wu, J. 2000. "Slippage Effects of the Conservation Reserve Program." American Journal of Agricultural Economics 82: 979-92. 